\title{
Epidemiology, Diagnosis \& Prevention of Newcastle Disease in Poultry
}

\author{
Mebrate Getabalew ${ }^{1}$, Tewodros Alemneh ${ }^{2 *}$, Dawit Akeberegn $^{3}$, Daniel Getahun ${ }^{1}$ and Derbie \\ Zewdie $^{1}$ \\ ${ }^{1}$ College of Agricultural and Natural Resources Science, Department of Animal Science, Debre Berhan University, Ethiopia
}

${ }^{2}$ Woreta Town Office of Agriculture and Environmental Protection, South Gondar Zone, Amhara Regional State, Ethiopia

${ }^{3}$ Debre Berhan City Municipality Office, Meat Inspection and Hygiene, North Shewa Zone, Amhara Regional State, Ethiopia

*Corresponding author: Tewodros Alemneh, Woreta City Office of Agriculture and Environmental Protection, South Gondar Zone, Amhara Regional State, Ethiopia.

To Cite This Article: Getabalew M, Alemneh T, Akeberegn D, Getahun D, Zewdie D. Epidemiology, Diagnosis \& Prevention of Newcastle Disease in Poultry. Am J Biomed Sci \& Res. 2019 - 3(1). AJBSR. MS.ID.000632. DOI: 10.34297/AJBSR.2019.03.000632. DOI: 10.34297/AJBSR.2019.03.000632

Received: April 18, 2019 | Published: May 16, 2019

\begin{abstract}
Newcastle disease is a contagious bird disease affecting many domestic and wild avian species. It is a zoonotic disease with widespread distribution. It is caused by avian Paramyxovirus serotype 1 virus which, with viruses of the other eight serotypes (avian paramyxovirus1-9), has been placed in the genus Avulavirus, sub-family Paramyxovirinae, family Paramyxoviridae. Virulent ND virus strains are endemic in poultry in most of Asia, Africa, and some countries of North and South America. Other countries, including the United States of America and Canada, are free of those strains in poultry. The strain of Newcastle pathogenicity can be classified into five pathotype: Asymptomatic enteric strain; Lentogenic strain; Mesogenic strain; Viscerotropic velogenic strain and Neurotropic velogenic strain. Clinical signs are extremely variable depending on the strain of virus, species and age of bird, management, concurrent disease, and pre-existing immunity caused by Paramixovirus with worldwide distribution affecting chickens of all age groups.

The transmission of ND occurs through respiratory aerosols, exposure to fecal and other excretions from infected birds, through newly introduced birds, selling and giving away sick birds and contacts with contaminated feed, water, equipment, cannibalism and clothing. Gasping, coughing, sneezing, rales, tremors, paralyzed wings and legs, twisted necks, circling; colonic spasms and complete paralysis are the clinical pictures of the disease. Newcastle disease may cause conjunctivitis in humans, when a person has been exposed to large quantities of the virus. The objective of this review is, therefore, to understand the epidemiology, clinical signs, diagnosis, prevent and control of Newcastle disease in poultry.
\end{abstract}

Keywords: Newcastle Disease; Strains; Pathogenicity; Avulavirus; Poultry; Zoonosis

\section{Introduction}

Based on the number of animals, poultry represents the largest domestic animal stock in the world [1]. Poultry represents an important sector in animal production, with backyard flocks representing a huge majority, especially in the developing countries. In these countries, villagers raise poultry to meet household food demands and as additional sources of incomes. Backyard production methods imply low biosecurity measures and high risk of infectious diseases, such as Newcastle disease (ND) or zoonosis such as Highly Pathogenic Avian Influenza (HPAI) [2]. Newcastle disease is a contagious bird disease affecting many domestic and wild avian species; it is transmissible to humans. ND is an important infectious disease of the poultry that is caused by virulent strains of Avian Paramyxovirus-1, which is a single strand non-segmented negative sense RNA virus [3]. Newcastle disease is a viral disease caused by the avian Paramyxovirus serotype 1 (APMV1), is one of the most important poultry diseases worldwide [4]. The epizootics of ND in poultry continue to occur in Asia, Africa, Central and South America while in Europe, sporadic epizootics occur [5]. In developing countries, human diet is deficient in the animal proteins; approximately $66 \%$ population has protein deficient diet [6].

Newcastle disease is an economically important disease and a major threat to poultry industry [7]. According to variation in strains of NDV, the rate of mortality and morbidity in a flock is different [8]. Pathotyping of NDV by reverse transcriptase polymerase chain reaction (RT-PCR) and restriction enzyme analysis along with decrease in egg production [9]. Isolation of virus and serological diagnostics, such as hemagglutination inhibition (HI) Test, Enzyme linked immune-sorbent assay (ELISA) and molecular diagnostic tests like real time PCR confirmed the presence of velogenic NDV [10]. The economic importance of ND may effect on the meat quali- 
ty of poultry. Availability of egg is increasing at rate of round about $4 \%$ annually [11]. In most developing countries, meat is a very important protein sources in diet of people because it is affordability and has high quality protein [12]. The objective of this review is to understand the ND causative agent, pathogenecity, clinical sign and how to prevent and control the ND, which concerned with the currently published research.

\section{History of Newcastle Disease}

The first outbreaks to be recognized and termed Newcastle disease (ND) occurred in poultry in 1926, in Java, Indonesia [13, 14], and in Newcastle-upon-Tyne, England [15]. However, there are earlier reports of similar disease outbreaks in Central Europe before this date [16]. In particular, Macpherson [17] attributes the death of all the chickens in the Western Isles of Scotland in 1896 as being due to Newcastle disease. It is possible; therefore, that ND did occur in poultry before 1926, but its recognition as a specifically defined disease of viral aetiology dates from the outbreaks during this year in Newcastle-upon-Tyne [18]. The name "Newcastle disease", (after the geographical location of the first outbreaks in Great Britain), was coined by Doyle as a temporary measure because he wished to avoid a descriptive name that might be confused with other diseases [19]. The name has, however, continued to be used although when referring to the ND virus (NDV), the synonym 'avian Paramyxovirus type 1' (APMV-1) is now often employed.

\section{Etiology}

Newcastle disease is caused by avian Paramyxovirus serotype 1 [APMV-1] viruses, which with viruses of the other eight APMV serotypes (APMV-2 to APMV-9), have been placed in the genus Avulavirus, sub-family Paramyxovirinae, family Paramyxoviridae, in the current taxonomy. Newcastle disease (ND) is a member of the family Paramyxoviridae in the genus Avulavirus. There are ten serotypes of avian paramyxoviruses designated APMV-I to APMV-10 and ND virus (NDV) has been designated APMV-1. Newcastle disease virus has also been categorized into five pathotypes based on clinical signs in infected chickens, designated:

a) viscerotropic velogenic,

b) neurotropic velogenic,

c) mesogenic,

d) lentogenic or respiratory and

e) asymptomatic. Pathotype groupings are rarely clear-cut $[18,20]$ (Table 1).

\begin{tabular}{|l|l|}
\hline \multicolumn{2}{|l|}{ Table 1: Characteristics of Newcastle Virus. } \\
\hline Temperature: & $\begin{array}{l}\text { Inactivated by } 56{ }^{\circ} \mathrm{C} / 3 \text { hours or } 60^{\circ} \mathrm{C} / 30 \\
\text { minutes. }\end{array}$ \\
\hline pH: & Inactivated by acid $\mathrm{PH} \leq 2$. \\
\hline $\begin{array}{l}\text { Che micals / Disinfec- } \\
\text { tants: }\end{array}$ & $\begin{array}{l}\text { Ether sensitive; inactivated by formalin, phe- } \\
\text { nolics and oxidizing agents (e.g.Virkon®); } \\
\text { chlorhexidine, sodium hypochlorite (6\%). }\end{array}$ \\
\hline Survival: & $\begin{array}{l}\text { Survives for long periods at ambient tem- } \\
\text { perature, especially in faeces. }\end{array}$ \\
\hline
\end{tabular}

Source: Alexander et al. [18].

\section{Epidemiology}

Many species of birds both domestic and wild Chickens are highly susceptible to disease; turkeys do not tend to develop severe signs. Game birds (pheasants, partridges, quail and guinea fowl) and parrots (order Psittaciformes) vary in susceptibility; cockatiels are susceptible Wild birds and waterfowl (order Anseriformes) may harbor virus sub-clinically; some isolates within certain genotypes have caused epiornitics within these species Young cormorants (Phalacrocorax spp.) have demonstrated disease associated with APMV-1 Disease has been recorded in ostriches (order Struthioniformes) and pigeons (order Columbiformes) are known to be susceptible Raptors are usually resistant to ND; except reports of acute disease in bearded vulture (Gypaetus barbatus), white-tailed sea eagle (Haliaeetus albicilla), a wild osprey (Pandion haliaetus) and some species of falcons Other birds known to have been affected by NDV include: gulls (order Charadriiformes), fowls (order Strigiformes), and pelicans (order Pelecaniformes). Passerine birds (order Passeriformes) are variable in their susceptibility; some species show no signs of disease but excrete NDV while others may develop severe disease Reports of deaths in crows and ravens (genus Corvus) have been recorded Acute ND has been recorded in penguins (order Sphenisciformes). The morbidity and mortality rates vary among species, and with the strain of virus. Humans may become infected; manifested by unilateral or bilateral reddening, excessive lachrymation, oedema of the eyelids, conjunctivitis and sub-conjunctival haemorrhage [10].

\section{Transmission}

Direct contact with secretions of infected birds; principally via ingestion (faecal / oral route) and inhalation, fomites: feed, water, implements, premises, human clothing, boots, sacks, egg trays/ crates, etc. Survival of agent is prolonged by presence of faeces; as in soiled eggshells. Virus is shed during the incubation period, during clinical stages and for a limited period during convalescence [18]. Fleas, rodent, insect and dog can also transmit NCD virus mechanical from infected faeces [21-23].

\section{Occurrence}

Velogenic NDV is endemic in areas of Mexico, Central and South America, widely spread in Asia, the Middle East and Africa, and in double-crested wild cormorants in the US and Canada. Lentogenic strains of NDV are worldwide in their distribution while widespread mesogenic pathotypes with a special adaptation to pigeons (i.e. pigeon Paramyxovirus) do not appear to infect other poultry readily [24].

\section{Pathogenicity and Clinical Signs}

The virulence of NDV strains varies greatly with the host. Chickens are highly susceptible, but ducks may be infected and show few or no clinical signs, even with strains lethal for chickens [25]. In chickens, the pathogenicity of ND is determined chiefly by the strain of virus, although dose, route of administration, age of the chicken, and environmental conditions all has an effect. In general, the more younger the chicken, the more susceptible to the disease. With virulent viruses in the field, young chickens may experience sudden deaths without major clinical signs; however, in older birds, 
the disease may be more protracted and with characteristic clinical signs. Breed or genetic stock does not appear to have a significant effect on the susceptibility of chickens to the disease [26]. The disease can vary from mild to severe. A highly contagious and severe form of the disease, called exotic Newcastle disease (END), is so deadly that many birds die suddenly without showing any signs of disease [27]. Clinical signs seen in birds infected with NDV vary widely and are dependent on factors such as: the virus/pathotype, host species, age of host, co-infection with other organisms, environmental stress and immune status (Figure 1).

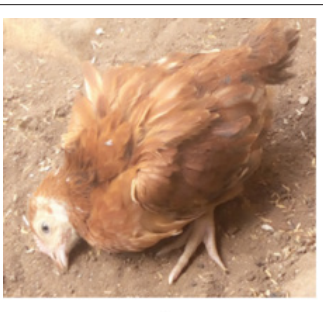

A

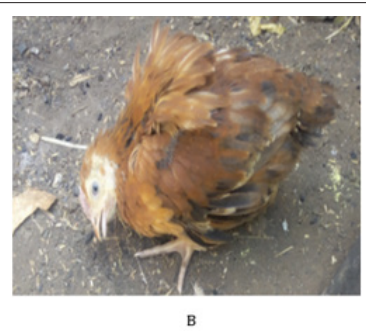

Figure 1: Chickens showing torticollis (twisting of the neck) due to Newcastle Disease virus infection at the age of 4 weeks.

Clinical signs alone do not present a reliable basis for diagnosis of ND. Morbidity and mortality depend on virulence of the virus strain, degree of vaccinal immunity, environmental conditions, and condition of the flock [18]. The clinical signs of the three most virulent pathotypes of avian Paramyxovirus (APMV-1) have been shown below [3,28]: Lentogenic strains: usually associated with subclinical disease marked by mild respiratory disease; coughing, gasping, sneezing and rales. If other co-infectious agents circulating, it can result in severe signs. Mortality is negligible. Mesogenicstrains: may produce cause acute respiratory disease and neurologic signs in some species Mortality rate is usually low $(<10 \%)$. If other co-infectious agents circulating, can result in severe signs. Velogenicstrains: most commonly cause severe disease in chickens with mortality; signs principally respiratory and/or nervous. Initial clinical signs vary but include lethargy, inappetence, ruffled feathers, oedema and injection of conjunctiva. As the disease progresses birds may develop greenish or white watery diarrhoea, dyspnoea and inflammation of the head and neck often with cyanotic discoloration.

In later stages of disease neurologic signs may be manifested as: tremors, tonic/clonic spasms, wing/leg paresis or paralysis, torticollis, and aberrant circling behaviour; also, be seen. Sharp drop in egg production; eggs contain a watery albumin and appear misshapen with abnormally coloured, rough or thin shells. These strains often result in sudden death, with few or no signs. Birds that survive serious infection may develop neurologic and partial or complete cessation of egg production. Morbidity and mortality rates may approach $100 \%$ in unvaccinated chickens [18]. The Strain of Newcastle Pathogenicity: The strain of Newcastle pathogenicity can be classified into five pathotype: Asymptomatic enteric strain a form that has sub-clinical enteric infection without clear symptoms; Lentogenic strain which virus present with the mild respiratory infections; Mesogenic stain which virus presents with rare nervous and respiratory signs while mortality rate is related with the age of susceptible birds(young birds are more susceptible as compare to adults); Viscerotropic velogenic strain which virus cause haemorrhagic intestinal lesions (Figure 2) and it is highly pathogenic; Neurotropic velogenic strain which virus cause high mortalities followed by respiratory and nervous signs [14].

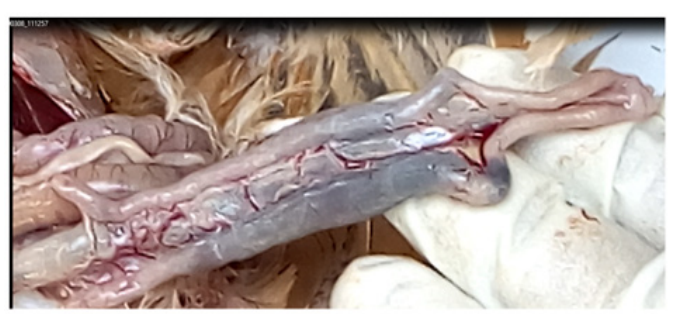

Figure 2: Hemorrhagic lesion in the Intestine of a chicken infected by Newcastle Disease Virus.

\section{Diagnosis}

\section{Clinical Sign and Lesions}

For a definitive diagnosis of ND, both virus isolation and laboratory characterization are necessary. Nevertheless, if the disease is known to be present in a given area, signs and lesions may be considered highly suggestive, especially for village chickens. Typical clinical signs are: a state of prostration and depression in the birds, with ruffled feathers; greenish white diarrhea; and, in survivors, the head turned to one side, a condition known as torticollis is very often seen, as are paralysis of the legs, wings or other neurological signs. Other typical characteristics of the disease include: rapid spread; death within 2-3 days; a mortality rate of over $50 \%$ in naive populations; and an incubation period of 3-6 days or, on rare occasions, 2-15 days $[18,29]$. On necropsy, typical lesions are mucus in the trachea, and usually hemorrhage in the intestine, particularly in the proventriculus. It should be borne in mind that all the preceding signs and lesions can be caused by other diseases [18].

\section{Serological Diagnosis}

In the absence of vaccination, the presence of specific antibodies against the ND virus indicates that the bird has been infected by the virus at some time, but not necessarily that it was suffering from the disease at the time of sampling. In practice, a high antibody titre is indicative of a recent infection. Two methods are used to measure antibody titres: the haemagglutination inhibition (HI) test, and the enzyme-linked immunosorbent assay (ELISA). For both, it is necessary to collect blood samples from the chickens. Catching village chickens for this purpose can present a problem. There are two approaches: where overnight housing is used, they can be retained in the morning; or children can be persuaded to catch them.

Blood samples are taken from the wing veins - a detailed description of the method is given in Alders and Spradbrow [22]. Cocks are usually harder to sample than hens. Blood can be drawn directly into a syringe or collected into a tube after piercing the vein with a needle. In both cases, the sample is subsequently placed nearly horizontally to allow clotting and to permit separation of the serum sample, which should be straw coloured. The serum sample should be kept cool until it can be frozen in the laboratory. 


\section{The haemagglutination Inhibition Test}

The HI test is based on the principle that the haemagglutinin on the viral envelope can bring about the agglutination of chicken red blood cells and that this can be inhibited by specific antibodies. V-bottomed microtitration plates are used. The serum samples are diluted in serial twofold dilutions in phosphate buffered saline and then a fixed quantity of viral antigen is added to each well. Usually 4 Haemagglutination Units are used, according to the method of Allan and Gough [30]. Following incubation, a suspension of red blood cells is added to each well and the plate is incubated again. In the absence of any antibody against the virus, haemagglutination occurs, appearing as a diffuse red colour at the bottom of the well. In the wells where the antibody against the virus is of a sufficient level, haemagglutination is inhibited and the red blood cells sediment and appear as a small pellet at the bottom of the well. The presence or absence of agglutination is accurately assessed by tilting the plates. Only those wells in which the RBCs stream at the same rate as the control wells (containing RBCs and PBS only) should be considered to show inhibition.

The HI titre is the reciprocal of the highest dilution of serum which completely inhibits haemagglutination and is usually and most conveniently expressed as the logarithm to the base 2 . Although the test is difficult to standardise between laboratories, the $\mathrm{HI}$ titre gives an indication of the immune status of the bird. A titre of $\log 23$ is indicative of protection and a titre of $\log 26$ or more suggests a recent infection by the virus. If no vaccination has taken place, diagnosis of the infection can be made on this basis, although it cannot be determined exactly when it took place. Sequential samples taken at different times can indicate whether the titre is rising - indicative of a recent infection - or declining [28]. When the HI titre is used as a measure of immunity (for example, when testing flock immunity following vaccination), it is recommended that an avirulent strain such as V4 or Ulster $2 \mathrm{C}$ be used as the viral antigen. The La Sota antigen has been found to be unsuitable for this purpose when vaccination is done by the same strain as it results in an overestimation of protective serum antibody titres [31].

\section{Enzyme Linked Immunosorbent Assay (ELISA) Test}

The ELISA works on the principle of recognition of anti-NDV antibodies, attached to a plate coated with viral antigen, by antibodies produced in another species against chicken antibodies. This anti-chicken antibody is conjugated to an enzyme that catalyzes a reaction, causing a change of colour which can then be read quantitatively on a photo spectrometer designed to read microtitration plates. The Animal Production \& Health Section of the Joint FAO/ IAEA Division has produced an ELISA kit for antibodies against NDV which is designed to be easily transportable and give uniform results under widely varying ambient temperatures. HI and ELISA titres show a good degree of correlation and ELISA titres can be interpreted in a similar way to HI titres [32].

\section{Virus Isolation}

The definitive diagnosis of ND is done through isolation and identification of the virus [33]. Tracheal and cloacal swabs are good sources of virus for isolation from living birds without hav- ing to kill them. A cotton-covered stick is inserted into the trachea or cloaca, and then put into a vial containing phosphate buffered saline plus penicillin and streptomycin. It is important to ensure that cloacal swabs are coated with faeces. These samples must be kept cool during transport to the laboratory where they should be stored at $4^{\circ} \mathrm{C}$ if they are to be processed within 48 hours or frozen at least at $-20^{\circ} \mathrm{C}$ until the isolation attempt. Although cloacal swabs or faeces should always be sampled, virus can also be isolated from homogenized organs from dead birds, chosen to reflect the clinical signs. Nine-day-old embryonated fowls' eggs are injected with 0.1 $\mathrm{mL}$ of the suspension into the allantoic cavity and returned to incubation. The eggs are candled twice daily. As dead eggs occur, they are chilled, together with $d$ all eggs after 5-7 days incubation, are chilled at $4^{\circ} \mathrm{C}$ at which point the allantoic fluid is then harvested and tested for its ability to haemagglutinate chicken red blood cells. Diagnosis is based on the inhibition of haemagglutination by specific anti-NDV serum. This proves infection of the bird by the virus, but does not indicate whether the virus is a pathogenic or avirulent strain [4].

\section{Pathogenicity Test}

The recommended in vivo test is the intracerebral pathogenicity index (ICPI) test in day-old chicks [34]. This involves the inoculation of virus derived from fresh infective allantoic fluid into the brain of ten day-old chicks from specific pathogen-free parents. Each bird is examined at 24-hour intervals for eight days and graded zero if normal, one if sick and two if dead. The index is the mean score per bird per observation over the 8-day period. The most virulent viruses give ICPI values approaching the maximum score of 2.0, while lentogenic viruses give values of, or close to, 0.0 [18]. Where day-old chicks are not available, the mean death time (MDT) in eggs (i.e. the mean time in hours for the minimum lethal dose to kill all the inoculated embryos), can be used as a guide to virulence. The MDT has been used to classify ND virus strains into velogenic (taking under 60 hours to kill); mesogenic (taking 60 to 90 hours to kill); and lentogenic (taking more than 90 hours to kill) [18].

\section{Prevention and Control}

The general approaches to the control of Newcastle disease are hygiene and vaccination, this is always important, especially in the control of NCD in semi-intensive systems where birds are confined within a fenced yard or house. Hygiene includes measures such as cleaning, disinfection, limiting access to wild birds, and personal hygiene of the farm staff. Vaccination in combination with appropriate hygiene measures, this remains the most effective way of controlling ND. Vaccination against ND would result in immunity against infection and replication of the virus. Realistically, ND vaccination usually protects the bird from the more serious consequences of disease, but virus replication and shedding may still occur [23].

\section{Vaccination}

Vaccination, initially with inactivated virus, was considered a possibility for the control of ND at the time of the apparent emergence of the virus. However, after the 1933 outbreak in England, an attenuated live vaccine was produced which was called strain $\mathrm{H}$. 
Later, the naturally occurring USA isolates of low virulence, Hitchner B1 (HB1) and La Sota, became the most used veterinary vaccines throughout the world. Fifty years or more have passed since vaccine was first used to protect village poultry against ND [35]. During this time, a wide variety of types of vaccine have been developed. Many, but not all, have been tested on village poultry. It is the purpose of this chapter to present an overview of the different kinds of vaccine available. It is not the intention to recommend a particular vaccine, but rather to try and outline the relative advantages and limitations of each, with particular reference to its use in the village situation and giving examples of how the different vaccines are employed.

The principle of vaccination against a viral disease is wellknown: to elicit an immunological response against the virus in a way that does not cause the disease. The simplest way to do this is to take the virus, kill it, and then inject it into the bird. This is an inactivated vaccine. Another approach is to select a naturally occurring virus that is not virulent enough to cause serious disease and infect the birds with this virus. This is a live vaccine. This latter approach can be taken further by taking a non-virulent natural virus and selecting a clone from the virus population with desirable properties, such as lack of vaccinal reactions, or heat tolerance. This is a cloned live vaccine. Finally, it is possible to genetically engineer a vaccine by, for example, taking part of the genetic material of the virus that codes for a surface antigen, and inserting this into another, different, virus to produce a recombinant vaccine [18].

These different approaches to vaccination have been applied to ND. There are three types of vaccines used for ND: live lentogenic, live mesogenic and inactivated vaccines. Live lentogenic vaccines are usually derived from field viruses that have been shown to have low pathogenicity for poultry but produce an adequate immune response. Typical vaccine strains are HB1, La Sota and F strain and some viruses from the asymptomatic enteric pathotype, which are usually based on the V4 or Ulster 2C viruses. However, these viruses have been frequently subjected to selection pressures by manufacturers in order to improve their immunogenicity or to enable their use by a particular method of application [18].

\section{Inactivated Vaccines}

Inactivated vaccines are produced by growing a ND virus in eggs, and then treating the infective allantoic fluid with an inactivating agent, such as formalin or betapropiolactone. An adjuvant, such as mineral oil, is usually then added to make the inactivated virus more immunogenic. Since the vaccine is no longer capable of replication or spread, it has to be injected individually into every bird needing vaccination. It is normally injected into the back of the thigh muscle (sometimes the breast muscle is used), using 0.3 or $0.5 \mathrm{ml}$ per bird. This requires some training, and cannot be done by every keeper of chickens without prior demonstration. Inactivated vaccines produce very high levels of antibodies against NDV, and provide good protection against the virulent virus $[18,36]$. In intensive poultry production, inactivated vaccines are usually applied after an initial priming vaccination with a live vaccine. In village poultry, however, good results in the absence of an initial vaccination with live vaccine have been reported [37]. The reason for this is probably, as serological surveys have shown where they have been carried out [38], that antibodies to the virus are already present in the village poultry as a result of previous infection by the wild virus.

Inactivated vaccines have been used extensively in village poultry, for example, in a successful project in Burkino Faso [39]. Although inactivated vaccine gives good protection, it is relatively expensive to produce. It also carries a slight risk to the user of accidental self-injection. While inactivated vaccines are, to some extent, heat sensitive, they are much less so than conventional live vaccines which makes transporting them to villages more feasible [36].

\section{Live Vaccines}

Live vaccines differ from inactivated vaccines in that they can replicate in the host. This is both an advantage and a disadvantage. It is an advantage in that it is not necessary to vaccinate every bird individually; the vaccinal virus can spread on its own from one bird to another. It is, however, a disadvantage in that, since an infection with a live virus is involved; this may result in clinical signs because of the innate virulence of the vaccine virus or by exacerbating other organisms that may be present, especially in the respiratory tract. The severity of this reaction depends therefore on the particular vaccinal strain used [40] and the presence or otherwise of concurrent infection with other pathogens. Another advantage of live vaccines compared to inactivated vaccines, is their ease of application as they can be applied to the drinking water or with an eye-dropper. Although NDV has essentially only one serotype, there is a wide difference in the pathogenicity of different strains, ranging from those that cause virtually no signs to those that kill within a few days. These have been classified, in order of increasing pathogenicity, into asymptomatic enteric, lentogenic, mesogenic and velogenic strains. The majority of live vaccines are derived from asymptomatic enteric or lentogenic strains, although some vaccines derived from mesogenic strains are still in use [36].

\section{Conventional Lentogenic Vaccines}

The level of vaccine reaction is an important consideration for intensive commercial poultry and because HB1 has very mild vaccinal reactions, it has been widely used for initial vaccination of intensive poultry. In a controlled trial in village poultry, HB1 provided effective protection against ND [37]. La Sota produces moderate vaccinal reactions, especially in immunologically naive birds and is not usually recommended for primary vaccination. In theory, La Sota would also be unsuitable for vaccinating a multi-age population, including young chicks which are inevitably seen in the village situation. This is because the virus spreads and it is not practical to isolate the adults from the chicks. In practice, the degree of reaction from La Sota as a primary vaccine depends on the residual level of antibodies, which could protect the birds from vaccinal reactions, and on the extent of other concurrent infections, such as Mycoplasma spp, pathogenic E. coli, or infectious bursal disease virus and other respiratory viruses. In intensive systems, vaccination using spray delivery systems which produce small particle sizes may also exacerbate the vaccine reaction [18].

Some lentogenic vaccines have been cloned by taking a single infectious virus and growing a homogenous population from it, 
with the aim of selecting a virus which gives less vaccinal reactions than a La Sota-like virus, while retaining its superior immunogenicity compared to a HB1-like virus. An example of this kind of vaccine is "clone 30" [18]. All conventional live vaccines have the disadvantage of needing to be kept at low temperatures to maintain their efficacy. This is not a problem for intensive poultry production in an industrial setting, but the maintenance of the "cold chain" during distribution can be very difficult in village settings, particularly where there is high ambient temperature. Another problem that is often encountered when using commercial vaccines in the village situation is that they are sold in vials containing 1000 or 500 doses, many more than the average village farmer needs. In fact, the packaging is a major component of the cost of manufacturing them, because a vial containing a smaller number of doses would not necessarily reduce the cost proportionally. Oil adjuvant, normally used with inactivated vaccines to improve immunogencicity, has also been tested with live vaccines and found to improve immunogenicity [41], but this combination has not been tested with village chicken

\section{Heat Tolerant Vaccines}

Some asymptomatic enteric viruses have been noted for their greater heat resistance than more conventional lentogenic viruses. This property has been enhanced by selection and cloning in the laboratory to produce heat tolerant vaccines. These have a distinct advantage in the village situation because it is possible to transport the vaccine without a cold chain. The most extensively used vaccine has been the NDV4-HR vaccine, which was pioneered in Malaysia, where a significant proportion of the village poultry was eventually covered by this vaccine [42]. The application was in feed, which, because of its thermo-stability, it was possible to pre-coat with the vaccine. The advantage of this method is that it is not necessary to catch the chickens before vaccinating them. The same vaccine has also been tried in other countries in South East Asia, but not always with the same success as in Malaysia. Tests of its application on a variety of foodstuffs have produced variable results [43]. The vaccine was also tested in some African countries, but applied by eyedrop and gave good protection against the virulent virus [44, 45]. Given the difference between African and Asian feeds, the variety of feeds within Africa, and the variable results with some feedstuffs in Asia, it seems that application of this type of vaccine is best done by eye-drop.

It can also be argued that the additional security provided by the vaccine is an incentive to invest in some form of housing, in which case catching the chickens is no longer a problem [18]. More recently, a similar vaccine to NDV4-HR, called I-2 [46], has been made available for local production in non-industrialized countries, which has the significant advantage of low cost. In trials in Ghana, Mozambique, Tanzania and Vietnam village chickens, vaccinated with strain I-2, were protected against artificial and field challenge with virulent virus [47-50].

\section{Mesogenic Vaccines}

Mesogenic strains have long been used for vaccination in the village situation. These produce severe vaccinal reactions in an immunologically naïve population, and the use of this kind of vaccine is not advisable in situations where chickens are without any immune protection against the virus. Normally mesogenic vaccines, such as Komarov [51] and Mukteswar [52] are used as secondary vaccines after a primary vaccination with a lentogenic vaccine [18].

\section{Recombinant Vaccines}

NDV has two surface glycoproteins, fusion [F] and haemagglutinin/neuraminidase [HN]. The genes coding for either of these can be inserted into a different kind of virus to make a recombinant vaccine. For example, the fusion gene inserted in herpes virus of turkeys produced a vaccine which gave good protection against virulent NDV [53]. One advantage of this technique is that the host virus may have better stability than NDV. Another advantage is that antigens for multiple different pathogens can be inserted into the same host virus to produce a single vaccine against several different diseases. Perhaps the most significant advantage for field use is that it is possible to monitor the response to the vaccine independently of the wild virus but in its presence, and conversely, it is possible to detect antibodies against the wild virus in the presence of vaccination. This is done by using an enzyme-linked immunoabsorbent assay (ELISA) that uses a purified antigen, and comparing the results with those of an ELISA using a whole virus antigen. For example, Makkay et al. [54] prepared an ELISA using only nucleocapsid protein of NDV as antigen. This detected antibodies against wild virus, but not antibodies against a recombinant fowl pox virus expressing HN glycoprotein. A parallel ELISA using whole virus as antigen detected antibodies against the vaccine. A disadvantage of recombinant vaccines is that where they have been developed commercially the cost is high [18].

\section{Vaccine Application}

Mass administration methods: In intensively developed commercial poultry industries, an important cost of vaccination is the administration. For this reason, mass application methods have been developed, primarily for live vaccines. Various forms of equipment are manufactured to generate coarse sprays, which allow mass application with minimum adverse reaction, although in some circumstances, mass application by fine sprays and aerosols are employed [55]. Application of live vaccines via drinking water is still employed in some areas, although in the commercial sectors, this gives some problems in preparing and cleaning the drinking water system, with a tendency for a less than uniform uptake [55].

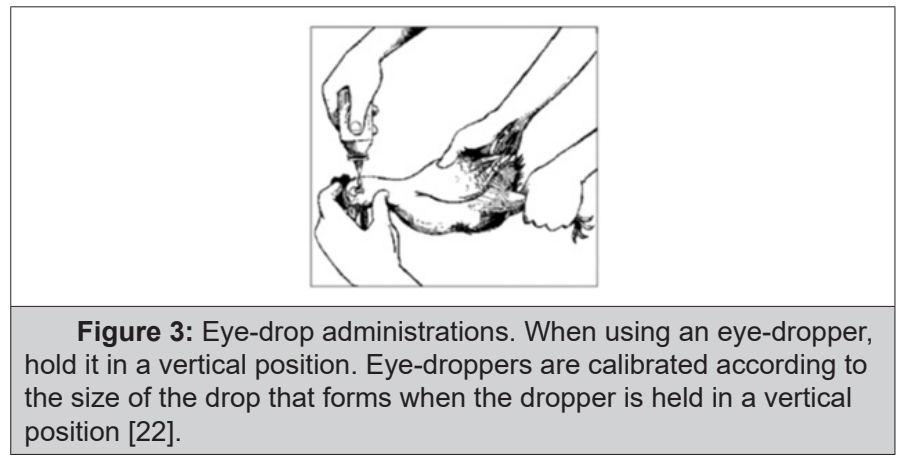

Eye-drop administration: Application of the vaccine by eyedrop methods is probably the most effective for live lentogenic vaccines (Figure 3). It ensures that the vaccine reaches the individu- 
al bird and, as a consequence, titres obtained are usually uniform throughout the flock. Correct dilution of the vaccine is critical. If eye-droppers are being used, they should be calibrated beforehand. In the absence of suitable eye-droppers, it is also possible to use the tip of a feather or a syringe (preferably a $1 \mathrm{~mL}$ syringe) to administer the drop. However, these two options should be seen as last resorts as they are inaccurate and cause considerable wastage of vaccine. Most live ND vaccines require re-vaccination at 3-4 monthly intervals. Eye-drop administration provides good protection because the vaccine passes to the Harderian gland just behind the eye, which in chickens is a key organ in the development of the immune response [18].

\section{Administration of the Vaccine via Drinking Water}

Vaccination by placing the live vaccine virus in the drinking water is easier than application to individual birds, but it provokes a lower level of immunity than eye-drop administration, has less uniform uptake and requires more frequent application. The vaccine should be given twice, initially 2-3 weeks apart, with re-vaccination at least every three months. It is important to remove drinking water from the chickens for 1-2 hours before the administration of the vaccine, and mix the vaccine with a volume of water that the chickens will be able to drink during one hour (usually 5-7 mL of water per bird). Always use fresh and clean water. In rural areas, it is best to give the drinking water in the morning just as the chickens are released from the chicken house. In areas with abundant surface water, chickens find their own source of drinking water and vaccination via water is not appropriate [18].

\section{Administration via feed}

Oral vaccination of chickens with thermo-stable vaccines (i.e. NDV4-HR and I-2) has been successful in some developing countries. Good veterinary services, local availability of suitable grains and recovery of virus from the grain are important considerations for successful oral vaccination. One problem with food-based ND vaccination is the low recovery of virus from some grains (especially maize), a consequence of either binding or inactivation. This method should be thoroughly tested before being used widely in the field. The vaccine must be given more often when administered via feed, making it more expensive, and survival rates in the face of an outbreak are lower than those achieved by eye-drop administration. Food used in any vaccination campaign should therefore be recommended by the Veterinary Authority. 7-10 grams of food per bird should be well mixed with the corresponding number of doses of appropriately diluted vaccine. With most grains, $1 \mathrm{ml}$. of fluid will efficiently moisten 10 grams of grain. The treated food is best given in the morning as the birds are leaving the roost. The vaccine should be given twice, initially 2-3 weeks apart, with re-vaccination at least every 2-3 months [28].

\section{Administration via injection}

Inactivated ND vaccines are administered by intramuscular or subcutaneous injection only (in the breast or the leg). Inactivated vaccines should be allowed to reach ambient temperature (approximately $28^{\circ} \mathrm{C}$ ) and the contents should be well shaken prior to use. If stored in a cool, dark location, an inactivated vaccine may retain its activity for 1-2 weeks outside a refrigerator. Inactivated vaccines are more effective in chickens which have previously received a living vaccine. Re-vaccination is usually done every 6 months [28].

Accidental injection into the vaccinator of inactivated vaccines based on emulsions formed with mineral oil can cause a serious localized reaction. These usually require incision and washing. Expert medical advice should be sought at once, and the doctor must be informed that the vaccine was a mineral oil emulsion. In many parts of Asia, mesogenic strains (for example, Mukteswar) of the ND virus are used and can be administered by injection only. This vaccine should be used in birds over eight weeks of age and following a primary vaccination with a lentogenic strain such as $F$ strain $[18,28]$.

\section{Conclusion}

Newcastle disease represents the most severe poultry disease responsible for marked economic losses in the world. ND may cause conjunctivitis in humans, when a person has been exposed to large quantities of the virus. Therefore, according to the concluding remark, the following points are recommended: regular vaccination should be carried out. Further study has to be conducted to know the depth (strength) of the epidemiological impact of those possible risk factors on the distribution of this disease.

\section{Acknowledgement}

Authors' deepest gratitude goes to friends and Debre Berhan University Staff members for their logistic supports.

\section{References}

1. (2012) FAO Stat. Production in Live animals.

2. Conan A, FL Goutard S, Sorn S, Vong (2012) Biosecurity measures for backyard poultry in developing countries: a systematic review. BMC Veterinary Research 8(1): 240.

3. Linde AM, M Munir, S Zohari, K Stahl, C Baule, et al. (2011) Complete genome characterisation of a Newcastle disease virus isolated during an outbreak in Sweden in 1997. Virus Genes 41(2): 165-173.

4. OIE (2009) Newcastle Disease: Aetiology, Epidemiology, Diagnosis, Prevention and Control References. OIE Technical Disease Cards.

5. Naveen KA, SD Singh, JM Kataria, R Barathidasan, K Dhama (2013) Detection and differentiation of pigeon paramyxovirus serotype1(PPMV-1) isolates by RT-PCR and restriction enzyme analysis. Tropical Animal Health and Production 45(5): 1231-1236.

6. Maqbool A (2002) Marketing of commercial poultry, poultry meat and eggs in Faisalabad City. MSc Thesis University of Agriculture, Pakistan.

7. Narayanan MS, M Parthiban, P Sathiya, K Kumanan (2010) Molecular Detection of Newcastle disease virus using Flinders Molecular Detection of Newcastle Disease virus using Flinders Technology Associates-PCR Technology Associates-PCR. J Veterinarski Arhiv, 80(1): 51-60.

8. Haque MH, MT Hossain, MT Islam, MA Zinnah, MSR Khan, et al. (2010) Isolation and Detection of Newcastle Disease virus from field outbreaks in Broiler and Layer chickens by Reverse transcription Polymerase Chain Reaction. Journal of Veterinary Medicine 8(2): 87-92.

9. Choi KS, EK Lee, WJ Jeon, JH Kwon (2010) Antigenic and immunogenic investigation of the virulence motif of the Newcastle disease virus fusion protein. J Vet Sci 11(3): 205-211.

10. Munir S, M Hussain, U Farooq, Q Zabid Ullah Jamal, M Afreen, et al. (2012) Quantification of Antibodies Against Poultry Haemagglutinating 
viruses by haemagglutination inhibition test in Lahore. African journal of microbiology research 6(21): 4614-4619.

11. Numan M, MA Zahoor, HA Khan, M Siddique (2005) Serological Status of Newcastle Disease in broilers and layers in Faisalabad and surronding districts. Pakistan Vet J 25(2): 55-58.

12. Thomazelli LM, JD Araujo, CS Ferreira, R Hurtado, DB Oliveira, et al. (2012) Molecular Surveillance of the Newcastle Disease Virus in Domestic and Wild Birds on the North Eastern Coast and Amazon Biome of Brazil. Brazilian Journal of Poultry Science 14(1): 01-07.

13. Kraneveld FC (1926) A poultry disease in the Dutch East Indies. Nederlands-Indische Bladen voor Diergeneeskunde 14(1): 42-48.

14. Ashraf A, Shah MS (2014) Newcastle Disease: Present status and future challenges for developing countries. African J Microbiol Res 8(5): 411416.

15. Doyle TM (1927) A hitherto unrecorded disease of fowls due to a filterpassing virus. J Comp Pathol Ther 40: 144-169.

16. Halasz F (1912) Contributions to the knowledge of fowl pest. Veterinary Doctoral Dissertation, Communications of the Hungarian Royal Veterinary School. Patria Budapest pp. 1-36.

17. Macpherson LW (1956) Some observations on the epizootiology of Newcastle disease. Can J Comp Med Vet Sci 20: 155-168.

18. Alexander DJ, Bell JG, Alders RG (2004) A Technology Review: Newcastle Disease. With Special Emphasis on its Effect on Village Chickens. FAO Animal Production and health Paper FAO. p: 161.

19. Doyle TM (1935) Newcastle disease of fowls. Journal of Comparative Pathology and Therapeutics 48: 1-20.

20. Center for food security and public health (CFSPH) (2016) IOWA State University College of Veterinary Medicine. Newcastle Disease Avian Paramyxovirus-1 infection, Goos.

21. Ullah S, Ashfaque M, Rahman SU, Akhtar M, Rehman A (2004) Newcastle disease virus in the intestinal contents of broilers and layers. Pakistan Veterinary Journal 24: 28.

22. Alders RG Spradbrow PB (2001) Controlling Newcastle Disease in Village Chickens: a field manual. Canberra, Australian Centre for International Agricultural Research. Monograph 82: 112.

23. Yune N, Abdela N (2017) Update on Epidemiology, Diagnosis and Control Technique of Newcastle Disease. Journal of Veterinary Science \& Technology 8: 429

24. Naveen KA, Singh SD, Kataria JM, Barathidasan R, Dhama K (2013) Detection and differentiation of pigeon paramyxovirus serotype-1 (PPMV-1) isolates by RT-PCR and restriction enzyme analysis. Trop Anim Health Prod 10: 01-06.

25. Higgins DA (1971) Nine Disease Outbreaks Associated with Myxoviruses among ducks in Hong Kong. Trop Anim Health Prod 3(4): 232-240.

26. Cole RK, FB Hutt (1961) Genetic differences in Resistance to Newcastle disease. Avian Dis 5(2): 205-214

27. OIE (2012) Manual of Diagnostic Tests and Vaccines for Terrestrial Animals. Newcastle disease.

28. Beard CW, Hanson RP (1984) Newcastle Disease. In: Diseases of Poultry 8th Edit MS Hofstad, HJ Barnes, BW Calnek, WM Reid, HW Yoder, et al. Eds. Iowa State University Press Ames, US pp. 452-470.

29. Allan WH, Gough RE (1974) A standard hemagglutination inhibition test for Newcastle disease. (2) Vaccination and challenge.

30. Vet Rec 95(7): 147-149.

31. Maas RA, Oei HL, Kemper S, Koch G, Visser L (1998) The use of homologous virus in the haemagglutination-inhibition assay after vaccination with Newcastle disease virus strain La Sota or Clone 30 leads to an over estimation of protective antibody titres. Avian Pathol 27,96): 625-631.
32. Bell JG, El Hakim, El Alaoui, M aouzi T (1991) An enzyme-linked immunosorbent assay for antibodies against Newcastle disease virus suitable for use in kit form in tropical countries. World Animal Review 69: 59-63.

33. Alexander DJ (1998) Newcastle disease and other avian Paramyxoviruses. In: A Laboratory Manual for the Isolation and Identification of Avian Pathogens 4th edition. Edited by DE Swayne, JR Glisson, MW Jackwood, JE Pearson, WM Reed, et al. American Association of Avian Pathologists: Kennet Square, USA PP: 156-163.

34. OIE (2000) Newcastle Disease. OIE Manual of Standards for diagnostic tests and vaccines OIE Pp: 221-232.

35. Placidi L, Santucci J (1952) Epidemiologie et prophylaxie vaccinale de la maladie de Newcastle au Maroc. Maroc Medicale 31: 3-7.

36. Alexander DJ (2003) Newcastle disease other Paramyxoviridae and Pneumovirus Infections In; Diseases of Poultry. $11^{\text {th }}$ Ed Iowa State press, USA Pp: 63-100.

37. Bell JG, Ait Belarbi D, Amara A (1990) A controlled vaccination trial for Newcastle disease under village conditions. Preventive Veterinary Medicine, 9(4): 295-300.

38. Bell JG, Mouloudi S (1988) A reservoir of virulent Newcastle disease virus in village chicken flocks. Preventive Veterinary Medicine 6(1): 37 42.

39. Verger M (1986) La prophylaxie de la maladie de Newcastle dans les elevages villageois en Afrique. Laviculteur 465: 44-48.

40. Westbury HA, Parsons G, Allan WH (1984) Comparison of the residual virulence of Newcastle disease vaccine strains V4, Hitchner B1 and La Sota. Australian Veterinary Journal 61(2): 47-49.

41. Peleg BA, Samina I, Brenner J (1993) Immunization of chickens with live Newcastle disease vaccine adjuvanted with oil. Vaccine 11(10): 10741076.

42. Ibrahim AL, Ideris A, Babjee AM (1992) An overview of the use of foodbased Newcastle disease vaccine in Malaysia. In: Spradbrow, PB, ed. Proceedings of an international workshop, Kuala Lumpur, Chienese 1991. Canberra ACIAR proceedings No 39: 75-79.

43. Spradbrow P (1992) A review of the use of food carriers for the delivery of oral Newcastle disease vaccine. In: Spradbrow, PB, ed. Proceedings of an international workshop, Kuala Lumpur, Chienese 1991. Canberra, ACIAR proceedings No 39: 18-20.

44. Saglid IK, Spalatin J (1982) Newcastle disease vaccination with the V4 strain in Malawi: laboratory and field studies. Avian Dis 26(3): 625-628.

45. Bell JG, Fotzo TM, Amara A, Agbede G (1995) A field trial of the heat resistant V4 vaccine against Newcastle disease by eye-drop inoculation in village poultry in Cameroon. Preventive Veterinary Medicine 25(1): 19-25.

46. Bensink Z, Spradbrow P (1999) Newcastle disease virus strain I-2- a prospective thermostable vaccine for use in developing countries. Vet Microbiol 68(1-2): 131-139.

47. Amakye Anim J, Awuni JA, Coleman T, Seddor V (2000) Ghanaian trials with a locally produced thermostable Newcastle disease vaccine (strain I-2) in chickens. 26th Animal Science Symposium, Ghana Animal Science Association. Kumasi University of Science and Technology.

48. Dias PT, Alders RG, Fringe R, Mata BV (2001) Laboratory and field trials with thermostable live Newcastle disease vaccines in Mozambique. In: RG Alders, PB Spradbrow, ed. SADC Planning Workshop on Newcastle Disease Control in Village Chickens. Proceedings of an International Workshop, Maputo, Mozambique, 2000 ACIAR Proceedings No 103, pp: 91-96.

49. Tu TD, Phuc KV, Dinh NTK, Quoc DN, Spradbrow PB (1998) Vietnamese trials with a thermostable Newcastle disease vaccine (strain I-2) in experimental and village chickens. Prev Vet Med 34(1-2): 205-214. 
50. Wambura PN, Kapaga AM, Hyera JMK (2000) Experimental trials with thermostable Newcastle disease virus (strain I2) in commercial and village chickens in Tanzania. Prev Vet Med 43(2): 75-83.

51. Saifuddin M, Chowdbury TI, Sarker AJ, Amin MM (1990) Protection conferred by vaccination with Blacksburg and Komarov strains of Newcastle disease virus against Newcastle disease in Bangladesh. Trop Anim Health Prod 22(4): 263-272.

52. Alexander DJ(1997) Newcastle Disease and other Avian Paramyxoviridae Infections. In: Diseases of Poultry $10^{\text {th }}$ Edition. Edited by BW Calnek, HJ Barnes, CW Beard, LR Mc Dougald, YM Saif, et al. Pp. 541-570.
53. Morgan RW, Gelb J, Pope CR, Sondermeijer PJ (1993) Efficacy in chickens of a herpesvirus of turkeys recombinant vaccine containing the fusion gene of Newcastle disease virus: onset of protection and effect of maternal antibodies. Avian Dis 37(4): 1032-1040.

54. Makkay AM, Krell PJ, Nagy E (1999) Antibody detection-based differential ELISA for NDV-infected or vaccinated chickens versus NDV HN-subunit vaccinated chickens. Vet Microbiol 66(3): 209-222.

55. Kouwenhoven B (1993) Newcastle Disease. In Viral Infections of Vertebrates Volume 3: Viral Infections of Birds. Edited by JB Mc Ferran, MS McNulty Series editor MC Horzinek, Elsevier Sci Pub Co, Amsterdam, Pp. 341-360. 